- Reports the orthodontic condition of children aged 12 and 15 years in the 2003

Children's Dental Health Survey.

- Examines the relationship between orthodontic condition and deprivation.

- Demonstrates considerable variation between professional and lay perceptions of orthodontic treatment need.

- Records trends in the types of appliance used since the 1983 Children's Dental Health survey.

\title{
The orthodontic condition of children in the United Kingdom, 2003
}

\author{
I. G. Chestnutt, ${ }^{1}$ D. J. Burden, ${ }^{2}$ J. G. Steele, ${ }^{3}$ N. B. Pitts, ${ }^{4}$ N. M. Nuttall ${ }^{5}$ and A. J. Morris ${ }^{6}$
}

\begin{tabular}{|l|}
\hline 1. The dentinal caries experience of children in the United Kingdom, 2003 \\
\hline 2. Non-carious tooth conditions in children in the UK, 2003 \\
\hline 3. Patterns of care and service use amongst children in the UK, 2003 \\
\hline 4. Oral health habits amongst children in the United Kingdom in 2003 \\
\hline 5. The reported impact of oral condition on children in the United Kingdom, 2003 \\
\hline 6. The orthodontic condition of children in the United Kingdom, 2003 \\
\hline
\end{tabular}

Background The 2003 Children's Dental Health Survey is the fourth in a series of decennial national children's dental health surveys in the United Kingdom.

Aims This paper reports on the orthodontic condition of children aged 12 and 15 years.

Methodology A representative sample of children across the UK were invited to participate in a clinical dental examination in school. Two thousand, five hundred and ninety-five 12-year-olds and 2,142 15year-olds were examined. Current and past orthodontic treatment and type of appliance worn were recorded. Orthodontic treatment need was assessed by the Modified IOTN in those not undergoing treatment. A postal questionnaire sought parents' views on the orthodontic condition of their children and perceived need for treatment.

Results At age 12,35\% were judged to have an orthodontic treatment need, $57 \%$ had no need and $8 \%$ were wearing an appliance. The corresponding figures at age 15 were, 21\% (need), 65\% (no need) and $14 \%$ (wearing appliance). A higher proportion of girls $(p<0.05)$ were wearing an appliance than boys. A greater proportion of 15-year-olds were undergoing treatment than in the 1993 and 1983 surveys and the use of fixed appliances had increased.

${ }^{1 *}$ Reader/Hon. Consultant in Dental Public Health, Cardiff University; ${ }^{2}$ Consultant Orthodontist and Senior Lecturer, Queen's University Belfast: ${ }^{3}$ Chair in Oral Health Services Research, University of Newcastle upon Tyne; ${ }^{4}$ Professor and Director, Dental Health Services Research Unit, Dundee; ${ }^{5}$ Reader, University of Dundee; ${ }^{6}$ Lecturer in Dental Public Health, University of Birmingham

*Correspondence to: Dr I. G. Chestnutt, Department Dental Health and Biological Sciences, Dental School, Cardiff University, Heath Park, Cardiff CF14 4XY

Email:chestnuttig@cardiff.ac.uk

(c) British Dental Journal 2006; 200: 609-612
Conclusions In this representative sample of UK children, one in five were still judged as having an orthodontic treatment need at age 15 years, as determined by the modified index of orthodontic treatment need. However, considerable variation was observed between professional and lay perceptions of need.

\section{INTRODUCTION}

In the year ending March 2004, over $£ 133$ million was spent on orthodontic treatment on those aged under 18 years in the General Dental Service (GDS) in England and Wales ${ }^{1}$ and overall orthodontic-related expenditure accounted for around 9\% of the total GDS budget. ${ }^{2}$ An understanding of trends in service provision and orthodontic treatment need is clearly important.

The 2003 Children's Dental Health survey, commissioned by the four United Kingdom Health Departments, is the fourth in a series of national surveys of children's oral health that have been carried out since 1973 in England and Wales and in the whole of the UK since 1983. This paper details the orthodontic condition of 12 and 15-year-old children in the 2003 survey and describes trends in orthodontic treatment recorded since the 1983 and 1993 surveys.

\section{METHODOLOGY}

Full details of the methodology, clinical criteria, sampling technique and the weighting procedures used in the survey are described elsewhere. ${ }^{3}$ In summary, the 2003 survey was based on a representative sample of children aged five, eight, 12 and 15 years attending government maintained and independent schools in the UK. The survey involved 557 primary schools and 132 secondary schools. In total, 3,129 12-year-old and 3,174 15-year-old children were sampled within participating schools and asked to take part in a dental examination.

In those aged 12 and 15 years, the clinical examination recorded current and past orthodontic treatment, including the type of appliance worn by children undergoing treatment. The orthodontic condition of those not wearing an appliance at the time of the survey was assessed using the Modified Index of Orthodontic Treatment Need (IOTN) which identifies those in definite need of orthodontic treatment in the same way as the original version of the Index of Orthodontic Treatment Need. ${ }^{4}$ However, this modified or simplified version of IOTN does not require the examiner to differentiate 
between those individuals with borderline need and no need for orthodontic treatment. The Modified IOTN has been shown to be more suitable for use in epidemiological surveys where the level of definite need for orthodontic treatment is most relevant. ${ }^{4}$

IOTN consists of two separate components: the Aesthetic Component (AC) and the Dental Health Component (DHC). The Aesthetic Component $(\mathrm{AC})$ determines the level of need for orthodontic treatment on aesthetic grounds by comparing the anterior teeth with 10 standard photographs, which represent a continuum of attractiveness; grading points eight to 10 are regarded as a definite need for treatment. ${ }^{5}$ The Dental Health Component (DHC) determines the need for orthodontic treatment on dental health grounds in relation to five occlusal traits: missing teeth, overjet, crossbite, displacement of contact points and overbite. Using the Modified IOTN, definite need for treatment is recorded if the subject has a DHC grade 4 or 5 and/or an AC grade 8-10. The 'borderline need for treatment' subjects are grouped with the 'no need for treatment' subjects into a 'no definite need for treatment' category.

The aesthetic and dental health components were examined separately and children were assessed in need of treatment on either aesthetic or dental health grounds alone, or on both.

In addition to the clinical examination, background information was sought on a random sub-sample of examined children via a postal questionnaire. The questionnaire was designed for completion by the parents, although older participants may have filled in the questionnaire themselves. Questions sought details of past care and opinions on the need for orthodontic treatment.

In view of the complexity of the sampling design and resultant weighting procedures, sampling errors were quantified using the statistics programme STATA, and were calculated using a design factor (deft) to take account of the complex sampling and weighting procedures. The statistical significances of differences in means and percentages between sub groups were tested by calculating the confidence interval for the differences observed, based on the standard errors calculated using the design factor. This ensured that sampling error was taken into account in the testing procedure. Where statistically significant differences between groups are reported, the $5 \%$ threshold $(\mathrm{p}<0.05)$ was used.

\section{RESULTS}

\section{Overall orthodontic condition}

In total 2,595 12-year-olds and 2,142 15-year-olds were examined. The overall orthodontic condition of these children is reported in Table 1. At the time of the survey, 8\% of 12-year-olds and $14 \%$ of 15 -year-olds were wearing an orthodontic appliance. A significantly higher percentage $(p<0.05)$ of girls than boys were wearing an appliance in both age groups.

Definite need for orthodontic treatment on dental health grounds and/or aesthetic grounds was recorded in 35\% of 12- year-olds and 21\% of 15-year-olds. Among 12-year-olds the definite need for treatment was broadly similar for both boys and girls. However, a significantly larger $(p<0.05)$ proportion of 15 -yearold boys (24\%) were judged to be in definite need of treatment than 15-year-old girls (19\%).

Among 12-year-olds, 57\% of all children participating in the survey were not wearing an orthodontic appliance and were not judged to have a definite need for orthodontic treatment. A higher proportion of such children was observed among 15-year-olds (65\%).

\section{Relationship between orthodontic condition and deprivation}

Schools involved in the survey were classified as either 'deprived' or 'non-deprived' based on the proportion of children receiving free school meals. Schools where over 30\% of children were eligible for free school meals were classed as 'deprived'. As shown in Table 2, among 12-year-olds the percentage of children wearing an appliance $(8 \%)$ or judged in need of orthodontic care (35\%) was the same, irrespective of school deprivation status. However, among 15-year-olds, a significantly lower proportion $(p<0.05)$ of children from deprived schools $(10 \%)$ were wearing an orthodontic appliance at the time of the survey compared with children from non-deprived schools (15\%).

\section{Trends in current and past orthodontic appliance wear}

Trends in current and past orthodontic treatment are shown in Table 3. Among 12-year-olds the proportion of subjects presently wearing an orthodontic appliance or who had previously worn an appliance has remained relatively stable. In the 1983 CDH survey, 14\% of 12-year-old subjects were found to be wearing an orthodontic appliance or had worn one in the past, $15 \%$ were recorded in 1993 and 13\% were recorded in 2003.

Among 15-year-olds the proportion of subjects with present or previous orthodontic appliance experience increased considerably between 1983 and 1993 from 22\% to 30\%. However, the 2003 survey recorded a more modest increase with $32 \%$ subjects found to have orthodontic appliance experience.

The types of orthodontic appliance worn by children wearing an appliance at the time of the survey examination are presented in Table 4. For both age groups examined in 2003, the majority of appliances were of the fixed variety, 72\% among 12-yearolds and 83\% among 15-year-olds. This represents an increase in the proportion of children undergoing therapy using fixed appliances compared with 1993. Among 12-year-olds in 2003, the proportion of children wearing removable appliances almost halved from $50 \%$ to $28 \%$, while the number who were wearing fixed appliances increased significantly $(\mathrm{p}<0.05)$ from $49 \%$ to $72 \%$. A similar pattern was observed for 15-year-olds. There was a significant decrease $(\mathrm{p}<0.05)$ in the proportion of 15 -year-olds

Table 1 Orthodontic condition among 12 and 15-year-olds by sex (United Kingdom, 2003)

\begin{tabular}{|c|c|c|c|c|c|c|}
\hline & \multicolumn{3}{|l|}{12} & \multicolumn{3}{|l|}{15} \\
\hline & Boys & Girls & All & Boys & Girls & All \\
\hline & \multicolumn{6}{|c|}{ Percentage of children: } \\
\hline Children undergoing orthodontic treatment at the time of the survey & 7 & 10 & 8 & 12 & 16 & 14 \\
\hline \multicolumn{7}{|l|}{ Children not undergoing orthodontic treatment at the time of the survey } \\
\hline Definite Need for Orthodontic Treatment (DHC 4\&t5 and/or AC 8-10) & 35 & 36 & 35 & 24 & 19 & 21 \\
\hline No Definite Need for Treatment (DHC 1-3 and AC 1-7) & 58 & 55 & 57 & 64 & 65 & 65 \\
\hline Weighted base & 1399 & 1291 & 2690 & 1257 & 1298 & 2555 \\
\hline
\end{tabular}


Table 2 Orthodontic condition among 12 and 15-year-olds by attendance at a 'deprived' school* (United Kingdom, 2003)

\begin{tabular}{|c|c|c|c|c|}
\hline & \multicolumn{2}{|c|}{ Not deprived } & \multicolumn{2}{|c|}{ Deprived } \\
\hline & 12 & 15 & 12 & 15 \\
\hline & \multicolumn{4}{|c|}{ Percentage of children: } \\
\hline Children undergoing orthodontic treatment at the time of the survey & 8 & 15 & 8 & 10 \\
\hline \multicolumn{5}{|l|}{ Children not undergoing orthodontic treatment at the time of the survey } \\
\hline $\begin{array}{l}\text { Definite Need for Orthodontic Treatment } \\
\text { (DHC 4\&5 and/or AC 8-10) }\end{array}$ & 35 & 20 & 35 & 24 \\
\hline No Definite Need for Treatment (DHC 1-3 and AC 1-7) & 56 & 65 & 58 & 67 \\
\hline Unweighted sample size & 2030 & 1741 & 565 & 401 \\
\hline
\end{tabular}

Table 3 Current and past orthodontic appliance wear among 12 and 15-year-olds (United Kingdom, 1983, 1993, 2003)

\begin{tabular}{llll}
\hline Age & \multicolumn{3}{l}{ Current or past orthodontic appliance wear } \\
\hline & 1983 & 1993 & 2003 \\
12 year olds & 14 & 15 & 13 \\
15 year olds & 22 & 30 & 32
\end{tabular}

wearing removable appliances from 37\% in 1993 to 18\% in 2003, while the proportion wearing fixed appliances increased from 68\% in 1993 to 83\% in 2003.

\section{Perceptions of orthodontic treatment need}

Discrepancies were evident between reported need for orthodontic treatment and the level of need as assessed by the modified index of orthodontic treatment need. The relationship between need as reported via the questionnaire and dentist's assessment of need on aesthetic and dental health grounds is recorded in Table 5. Among 12 year-olds, 12\% of those judged by clinical examination to have no definite need for treatment were thought to require their teeth straightening by parents/children responding to the questionnaire. In addition, 58\% of 12-yearolds recorded as in definite need of treatment by the examining dentists, were thought not to require treatment by respondents to the questionnaire. Among 15 -year-olds, 10\% of children judged not to be in definite need of treatment by clinical examination, were reported as needing teeth straightened by parents/children, while for those with a definite clinical treatment need, just one in five questionnaire respondents suggested the need for orthodontic treatment.

\section{DISCUSSION}

The data presented in this paper, provide a snapshot of the orthodontic condition of a representative sample of UK 12 and 15-year-olds in 2003. In contrast to the 1983 and 1993 surveys where all age years were examined, in 2003, only representative age cohorts, 12 and 15 years, were sampled for orthodontic assessment. At age 12, a good number of children will not as yet have commenced orthodontic therapy and by age 15, many will have completed treatment. A 1991 analysis of Dental Practice Board records, showed that the mean age at commencement of treatment in the General Dental Service in England and Wales was 12.7 years, with a mean treatment duration of 1.3 years. ${ }^{6}$ For this reason, treatment need at age 15 provides a more appropriate measure of unmet need. If it is assumed that the $8 \%$ of 12 -year-olds already wearing an appliance at the time of the survey were in need of treatment, coupled with the 35\% not undergoing treatment but judged as in need, then the overall treatment need at age 12 is $43 \%$. That $21 \%$ of 15 -year-olds are still regarded as in need of treatment suggests that overall about $50 \%$ of the treatment need, as judged by simplified IOTN is being met.

The significantly greater unmet need in boys (24\%) compared with girls (19\%) at age 15 years reflects a greater up take of treatment by girls as evidenced by a greater number of girls wearing appliances at both age 12 and 15 . These findings agree with previous surveys which have also found that more females than males enter orthodontic treatment in the UK. ${ }^{5-7}$

The influence of socio-economic factors on orthodontic treatment provision and unmet treatment need, whereby at age 15 , appliance wear was higher in those attending 'non-deprived schools' and treatment need was higher in 'deprived schools' con-

Table 4 Types of orthodontic appliance worn by children wearing an orthodontic appliance at the survey examination (United Kingdom, 1993, 2003)

\begin{tabular}{|c|c|c|c|c|}
\hline & \multicolumn{4}{|l|}{ Age } \\
\hline & \multicolumn{2}{|l|}{12} & \multicolumn{2}{|l|}{15} \\
\hline & 1993 & 2003 & 1993 & 2003 \\
\hline & \multicolumn{4}{|c|}{ Percentage of children wearing an appliance with each type of appliance } \\
\hline Fixed & 49 & 72 & 68 & 83 \\
\hline Removable & 50 & 28 & 37 & 18 \\
\hline Other & 2 & 3 & 2 & 4 \\
\hline Base ( $100 \%$ of children wearing an appliance) & 109 & 191 & 87 & 250 \\
\hline Don't know what type of appliance ( $n$ ) & & 2 & & 9 \\
\hline $\begin{array}{l}\text { Children undergoing treatment at the time of the survey but not wearing their } \\
\text { appliance at the survey examination ( } n \text { ) }\end{array}$ & & 10 & & 23 \\
\hline
\end{tabular}


Table 5 Perceived need for orthodontic treatment by dentist's assessment of definite orthodontic treatment need (DHC 4Ct5 and/or AC 8-10) in those children not already undergoing treatment. (United Kingdom 2003).

\begin{tabular}{|c|c|c|}
\hline \multirow[t]{3}{*}{ Reported need by respondents to questionnaire } & \multicolumn{2}{|c|}{ Level of treatment need (Modified IOTN) } \\
\hline & $\begin{array}{l}\text { No definite need } \\
\text { for treatment }\end{array}$ & $\begin{array}{l}\text { Definite need for } \\
\text { treatment }\end{array}$ \\
\hline & \multicolumn{2}{|c|}{ Percentage of respondents agreeing } \\
\hline \multicolumn{3}{|l|}{12 year olds } \\
\hline Teeth need straightening & 12 & 42 \\
\hline Teeth alright & 88 & 58 \\
\hline \multicolumn{3}{|l|}{15 year olds } \\
\hline Teeth need straightening & 10 & 20 \\
\hline Teeth alright & 90 & 80 \\
\hline
\end{tabular}

firm the findings of previous studies. ${ }^{6,8,9}$ However, it is interesting that at age 15 the difference in unmet need between deprived and non-deprived schools is just 4\%. The link between deprivation and orthodontic treatment is complex. Whether the findings reflect differences in perceived need, or differences relating to the availability of treatment, cannot of course be determined from a survey such as this. Previous research has identified that the dental attendance pattern of a child and their mother is influential in determining whether a subject receives orthodontic treatment or not. ${ }^{10}$ Among children attending 'deprived schools', less frequent dental attendance may explain the higher unmet treatment need. However this does not explain whether this relates to an underlying shortage of services in certain areas or variations in personal choices and priorities in health care. The two may be inter-related.

It is interesting to note the trends in appliance wear recorded between 1983 and 2003. Although a relatively large increase in appliance experience was noted between 1983 and 1993 this trend has slowed down over the last decade. One of the main reasons for this slow down in the rate of treatment uptake is likely to be related to the increased use of fixed appliances that was noted in the present survey. The increased use of fixed appliances must be seen as a welcome trend because of the more consistent success achieved with dual arch fixed appliances. ${ }^{6}$ However, on average the duration of fixed appliance treatment is greater than treatment with removable appliances ${ }^{11}$ which will inevitably impact on individual operator caseloads.

There were obvious discrepancies between parent/children's views on the need for treatment and those recorded by the examining dentists and the potential reasons for this merit further discussion. In both age groups, a large proportion of questionnaire respondents reported that they did not perceive a need for orthodontic treatment and yet according to IOTN these children were in the definite need for treatment category. Differences in aesthetic expectations between members of the public and dentists are known to exist. ${ }^{12}$ However, it is also the case that occlusal indices such as IOTN record need on the basis of the dental health risk of certain occlusal features as well as the aesthetic impact of the dental appearance. Occlusal features which are recorded as needing orthodontic correction in the Dental Health Component of IOTN such as deep traumatic overbite, severe posterior crossbite or impacted teeth may not have any aesthetic implications. These disparities between need and demand for orthodontic treatment (Table 5) raise some interesting questions. Of the 15-year-olds judged by professionals as in need of treatment, $80 \%$ of the respondents to the questionnaire thought the teeth 'alright'. It may be that by age 15 , although aware that their occlusion is less than perfect, children and/or their parents have accepted the situation. Is there, therefore, the requirement for education to bridge the gap between lay and professional judgement of need? For example, to what extent do patients or their parents appreciate the merits of orthodontic treatment other than improved aesthetics? Such questions cannot be answered by the present survey and there is scope for examining what constitutes agreed need between parents, young people and professionals.

\section{CONCLUSIONS}

This study provides an overview of the orthodontic condition of children in the United Kingdom in 2003. The proportion of children undergoing treatment at age 15 has increased steadily over the past 20 years and the majority of children receiving orthodontic care are now treated with fixed appliances. Nevertheless, an unmet treatment need exists, one in five 15-year-olds being recorded as having a treatment need.

This work was undertaken by a consortium comprising the Office for National Statistics and the Dental Schools of the Universities of Birmingham, Cardiff, Dundee and Newcastle and the Dental Health Services Research Unit, Dundee who received funding from the United Kingdom Health Departments; the views expressed in this publication are those of the authors and not necessarily those of the Health Department.

1. Dental Practice Board. Dental Practice Board: GDS Statistics - Orthodontics, 2004 www.dpb.nhs.uk/gds/ortho_fees.shtml

2. Audit Commission. Dentistry - primary dental care services in England and Wales. London: 2002.

3. Office for National Statistics. Children's Dental Health Survey 2003 - Technical report, 2004. www.statistics.gov.uk/CHILDREN/dentalhealth

4. Brook $\mathrm{PH}$, Shaw W C. The development of an index of orthodontic treatment priority. Eur J Orthod 1989; 11:309-320.

5. Roberts E E, Beales J G. Dixon L et al. The orthodontic condition and treatment status of a sample of 14-year-old children in North Derbyshire. Comm Dent Health 1989; 6: 249-256.

6. Turbill E A, Richmond S, Wright J L. A closer look at General Dental Service orthodontics in England and Wales. I: Factors influencing effectiveness. Br Dent $J$ 1999; 187: 211-216.

7. Burden D J, Pine C M, Burnside G. Modified IOTN: an orthodontic treatment need index for use in oral health surveys. Comm Dent Oral Epidemiol 2001; 29: 220-225.

8. Mandall N A, McCord J F, Blinkhorn A S et al. Perceived aesthetic impact of malocclusion and oral self-perceptions in 14-15-year-old Asian and Caucasian children in greater Manchester. Eur J Orthod 1999; 22: 175-183.

9. Turbill E A, Richmond S, Wright J L. Social inequality and discontinuation of orthodontic treatment: is there a link? Eur J Orthod 2003: 25: 175-183.

10. Breistein B, Burden D J. Equity and orthodontic treatment: a study among adolescents in Northern Ireland. Am J Orthod Dentofacial Orthop 1998; 113: 408-413.

11. Turbill E A, Richmond S, Wright J L. The time-factor in orthodontics: what influences the duration of treatments in National Health Service practices? Comm Dent Oral Epidemiol 2001; 29: 62-72.

12. Hunt 0 , Hepper $P$, Johnston C etal. The Aesthetic Component of the Index of Orthodontic Treatment Need validated against lay opinion. Eur J Orthod 2002; 24: 53-59. 